\title{
Why Women Choose to Delivery at Home in India: A Study of Prevalence, Factors, and Socio-Economic Inequality
}

\author{
Ratna Patel \\ International Institute for Population Sciences \\ Strong P Marbaniang \\ International Institute for Population Sciences \\ Shobhit Srivastava \\ International Institute for Population Sciences \\ Pradeep Kumar \\ International Institute for Population Sciences \\ Shekhar Chauhan ( $\nabla$ shekhariips2486@gmail.com ) \\ International Institute for Population Sciences https://orcid.org/0000-0002-6926-7649
}

Research article

Keywords: Place of delivery, Home delivery, Socio-economic inequality, India

Posted Date: February 17th, 2021

DOl: https://doi.org/10.21203/rs.3.rs-243914/v1

License: (9) This work is licensed under a Creative Commons Attribution 4.0 International License.

Read Full License 


\title{
Why women choose to delivery at home in India: A study of prevalence, factors, and socio-economic inequality
}

\author{
Ratna Patel \\ PhD Research Scholar \\ Department of Public Health and Mortality Studies \\ International Institute for Population Sciences \\ Mumbai, India \\ ORCID: 0000-0002-5371-7369 \\ Strong P Marbaniang \\ PhD Research Scholar \\ Department of Mathematical Demography and Statistics \\ International Institute for Population Sciences \\ Mumbai, India \\ Shobhit Srivastava \\ PhD Research Scholar \\ Department of Mathematical Demography and Statistics \\ International Institute for Population Sciences \\ Mumbai, India \\ ORCID: 0000-0002-7138-4916 \\ Pradeep Kumar \\ $\mathrm{PhD}$ Research Scholar \\ Department of Mathematical Demography and Statistics \\ International Institute for Population Sciences \\ Mumbai, India \\ ORCID: 0000-0003-4259-820X \\ Shekhar Chauhan* \\ PhD Research Scholar \\ Department of Population Policies and Programmes \\ International Institute for Population Sciences \\ Mumbai, India \\ Email: shekhariips2486@gmail.com \\ ORCID: 0000-0002-6926-7649
}

*denotes the corresponding author 


\section{Why women choose to delivery at home in India: A study of prevalence, factors, and socio-economic inequality}

\section{Abstract:}

Background: Most of childbirth complications usually arise during the time of delivery and are difficult to predict, but can be effectively managed through delivery at the health facility equipped with skilled birth attendants placed in an enabling environment. Despite many efforts put by the Government to reduce maternal and neonatal deaths through institutional birth deliveries, statistics suggest that these deaths are still very high in India. This study sought to determine the prevalence of home births and identifying the factors influencing women choice.

Methods: Data from the National Family Health Survey (NFHS) conducted during 2005-06 and 2015-16 was used in the study. The respondents were women 15-49 years, a sample of 36,850 and 1, 90,898 women from two time period were included in the study. Multivariate logistic regression was used to determine the factors influencing home delivery.

Results: Women's who give birth at home has reduced by $39.6 \%$ from $58.5 \%$. As compared to women below 18 years, those who were above 25 years were less likely to give birth at home [OR: 0.57; CI: 0.49-0.68] and [OR: 0.76; CI:0.70-0.82]. Women with full ANC visit were less likely to give birth at home as compare to women with no ANC visit [OR: 0.34; CI: 0.28-0.41] and [OR: 0.41; CI: 0.38-0.45]. In central India the odds of delivering babies at home was high in 2005-06 [OR: 1.15; CI: 1.01-1.32] whereas in 2015-16 the situation was opposite [OR: 0.92; CI: $0.87-0.98$ ] in reference to women from north India.

Conclusion: There is a need to promote institutional deliveries, special focus to be given to poor women, women with higher parity, uneducated women, and rural women. Much work needs to be done in the rural parts of the country as rural women were more likely to opt for home delivery than their counterparts.

Keywords: Place of delivery; Home delivery; Socio-economic inequality; India 


\section{Why women choose to delivery at home in India: A study of prevalence, factors, and socio-economic inequality}

\section{Background:}

The choice of place of delivery has been mostly found to be associated with maternal and neonatal outcomes. Maternal and neonatal mortality arising from inadequate health services has been identified as the global challenge that has seen Southern Asian countries contributes about $20 \%$ of global maternal deaths and $38 \%$ of global neonatal deaths in 2017 [1], [2]. Most authors highlighted the factors associated with this maternal and fetal deaths is the occurrence of home deliveries as they are mostly unplanned, accidental and unhygienic [3], [4]. According to the latest estimates, over 800 women around the world died everyday from complications in pregnancy and childbirth [1]. Globally the major reasons of maternal deaths are haemorrhage, hypertensive disorders, sepsis, unsafe abortion and embolism [5]. These complications usually arise during the time of delivery and are difficult to predict, but can be effectively managed and deaths can be prevented through delivery at the health facility equipped with skilled birth attendants placed in an enabling environment [6]. This raise concerns that if women give birth unattended by trained health workers, the risk of dying due to complications arising during childbirth may not be prevented. Moindi et al., (2015) acknowledge that the presence of skilled birth attendant during childbirth in a hygienic environment with necessary skills and equipment to identify and manage any emerging complications reduce the likelihood of women and child death during the delivery process [7]. Most pregnancy and birth complications are timely manage in the health facility [8], unlike home delivery where women are not attended by skilled birth attendant and the chances of complications resulting to death is high [9], [10].

The Government of India launched the Janani Suraksha Yojana (JSY) programme in 2005 with the objective to reduce maternal and neonatal mortality by encouraging institutional delivery [11]. An evaluation of this cash incentive programme in 2007-2008 shows an increase 
of Anti Natal Care (ANC) visits and institutional delivery [12]. However, this has not translated into reduction of maternal and neonatal mortality rate [13], as these rates are still being reported significantly high in India [1], [2]. The global estimated shows that there were 295,000 maternal deaths in 2017, India alone contributes about $12 \%(35,000)$ of global maternal deaths [1], and about $26 \%$ of the global neonatal deaths [14].

Many studies related to this subject using qualitative and quantitative approach have argued that there are factors that influence the choice of place of delivery [15]-[17]. The significant factors that have been indentified are: distance to health facilities (women who have to travel long distance to the health facilities end up giving birth at home) [6]: cost (when the expenses are high and the delivering mother is of low income groups they might not afford to pay the hospitalisation bills) [18] or (giving birth at home may be attributed to unavailability of cash for transportation even in a case of free maternal health services) [19]: level of knowledge and access to ante natal care (where mothers with lower knowledge about safe delivery are more likely to delivery at home as compare to those with higher knowledge) [20], [21]. Further, Das \& Hammer, (2014) explained that people were not using institutional delivery because of the quality of health facility is low [22]. Previous study also acknowledge that the quality of care received during pregnancy has been found to positively associated with the use of skilled delivery care [10].

There is dearth of knowledge as to why women still give birth at home in India despite government interventions in promoting institutional delivery by giving cash assistance. Existing studies on the subject of home delivery in India were mostly based from micro level data from different sections of the country and the results may not represent the entire population [16], [23], [24]. Hence this study tries to fill this gap by using the data from the national representative survey to determine the prevalence of home birth among women and identifying the factors influencing their choice. Identifying the factors which determine the 
choice of place of delivery will help in reducing maternal and neonatal mortality target of the Sustainable Goal 3 through increase child birth at health facility supervised by skilled birth attendant.

\section{Methods:}

\section{Data}

The data for this study has been derived from the two rounds of the National Family Health Survey (NFHS): NFHS-3 and NFHS-4, which were carried out in 2005-06 and 2015-16 respectively. The NFHS series is a cross-sectional national representative survey, conducted under the stewardship of the Ministry of Health and Family Welfare (MoHFW), Government of India, and provides the information on population, health and nutrition for India and each state/union territory. NFHS-3 gathered information from 124,385 women aged 15-49 years whereas in NFHS-4, interviews were conducted with 601,509 households, and 699,686 women aged 15-49 years. The survey used a two-stage stratified sampling procedure for the selection of the sample where the sampling frame was taken from the national census for the selection of primary sampling units (PSUs). PSUs were villages in rural areas and Census Enumeration Blocks (CEBs) in urban areas. PSUs with fewer than 40 households were linked to the nearest PSU. Within each rural stratum, villages were selected from the sampling frame with probability proportional to size (PPS). The detailed methodology, sampling design and data collection procedure, was published in the survey report. The effective sample size for the study was 36,850 and 190,898 women aged 15-49 years who gave recent child during five year preceding the survey for NFHS 2005-06 and 2015-16, respectively.

\section{Outcome variable}

The question was asked to women 'Where did you give birth to (NAME)?' The responses were home (included your home, parents' home and other home), public health sector (included 
govt./municipality hospital, government dispensary, uhc/uhp/ufwc, chc/rural hospital/block

147 phc, phc/additional phc, sub-centre, other public sector health facility) and private (included hospital/maternity home/clinic, other private sector health facility, ngo or trust hospital/clinic, other). The outcome variable was dichotomous and coded as ' 1 ' if women delivered at home and ' 0 ' otherwise.

\section{Predictor variables}

The predictors included age at first birth ( $<18$ years, 18-24 years and 25 years or more), parity (first, second, third and four or more), antenatal care (no, partial and full), skill birth attendant (no and yes), mass media exposure (no and yes), educational attainment (no schooling, primary, secondary, and higher), caste (Scheduled Caste, Scheduled Tribe, Other Backward Class, others), religion (Hindu, Muslim, and others), wealth index (poor, middle, rich), place of residence (urban and rural), and region (North, Central, East, Northeast, West, and South).

\section{Statistical analysis:}

The bivariate and multivariate logistic regression analysis were applied to assess the factors associated to home deliveries. In bivariate analysis, a chi-square test was performed to assess the association of socio-demographic factors with home deliveries. The study included variables in multivariate analysis that were statistically significant $(\mathrm{p}<0.05)$ in bivariate analysis. The adjusted odds ratio with a $95 \%$ confidence interval were presented in results.

\section{Concentration Index (CI)}

Income related inequality in home delivery was quantified by the concentration index (CI) and the concentration curve (CC), using the wealth score as the socio-economic indicator and binary outcome as home delivery. The concentration curve is obtained by plotting the cumulative proportion of poor health against the cumulative proportion of the population ranked by the socio-economic indicator. The concentration index can be written as follows: 


$$
C=\frac{2}{\mu} \operatorname{cov}\left(y_{i}, R_{i}\right)
$$

171 Where, $\mathrm{C}$ is the concentration index; $y_{i}$ is the outcome variable index; $\boldsymbol{R}$ is the fractional rank 172 of individual $\boldsymbol{i}$ in the distribution of socio-economic position; $\boldsymbol{\mu}$ is the mean of the outcome 173 variable of the sample and $\operatorname{cov}$ denotes the covariance.

174 If the curve lies above the line of equality, the concentration index takes a negative value, 175 indicating a disproportionate concentration of inequality among the poor (pro-rich). 176 Conversely, if the curve lies below the line of equality, the concentration index takes a positive 177 value, indicating a disproportional concentration of inequality among the rich (pro-poor). In 178 absence of socio-economic related inequality, the concentration index is zero.

Decomposition of the concentration index

The study used Wagstaff decomposition analysis to decompose the concentration index.

Wagstaff's decomposition demonstrated that the concentration index could be decomposed into the contributions of each factor to the income-related inequalities. Based on the linear regression relationship between the outcome variable $y_{i}$, the intercept $\alpha$, the relative contribution of $x_{k i}$ and the residual error $\varepsilon_{i}$

$$
y_{i}=\alpha+\sum \beta_{k} x_{k i}+\varepsilon_{i}
$$

Where $\varepsilon_{i}$ is an error term, given the relationship between $y_{i}$ and $x_{k i}$, the CI for $\mathrm{y}(\mathrm{C})$ can be rewritten as:

$$
C=\sum\left(\frac{\beta_{k} \bar{x}_{k}}{\mu}\right) C_{k}+\frac{G C \varepsilon}{\mu} / \mu
$$


Where $\mu$ is the mean of $y_{i}, \bar{x}_{k}$, is the mean of $x_{k}, \beta_{k}$ is the coefficient from a linear regression of outcome variable, $C_{k}$ is the concentration index for $x_{k}$ (defined analogously to $\mathrm{C}$, and $\mathrm{GC}_{\varepsilon}$ is the generalized concentration index for the error term $\left(\varepsilon_{i}\right)$.

Here $\mathrm{C}$ is the outcome of two components: First, the determinants or 'explained' factors. The explained factors indicate that the proportion of inequalities in the outcome (home delivery) variable is explained by the selected explanatory factors, i.e., $\mathrm{x}_{\mathrm{k}}$. Second, a residual or 'unexplained' factor $\left(\frac{G C \varepsilon}{\mu} / \mu\right)$, indicating the inequality in health variable that cannot be explained by selected explanatory factors across various socioeconomic groups.

\section{Results:}

Table-1 reveals the socio-demographic profile of study population in India. In 2005-06 almost $8.2 \%$ of women had age at first birth of 25 years or more whereas the in $2015-16$ it was $15.4 \%$. In 2005-06 women with parity four and more was $27.8 \%$ whereas in $2015-16$ it decreased to 15.3\%. Women who received full ante-natal care (ANC) increased from $11.2 \%$ in $20115-06$ to $19.5 \%$ in $2015-16$. Women who delivered babies using skilled birth attendant increased from $49.8 \%$ in $20115-06$ to $83.4 \%$ in $2015-16$. Women with no education substantially decreased from $2005-06(47.4 \%)$ to $2015-16(27.6 \%)$.

\begin{tabular}{|c|c|c|c|c|}
\hline \multirow{2}{*}{$\begin{array}{l}\text { Background } \\
\text { characteristics }\end{array}$} & \multicolumn{2}{|c|}{ 2005-06 } & \multicolumn{2}{|c|}{ 2015-16 } \\
\hline & Percentage & Sample & Percentage & Sample \\
\hline \multicolumn{5}{|l|}{ Age at first birth } \\
\hline$<18$ years & 30.5 & 9,132 & 13.0 & 23,627 \\
\hline $18-24$ years & 61.3 & 22,829 & 71.6 & $1,35,243$ \\
\hline 25 or more years & 8.2 & 4,889 & 15.4 & 32,028 \\
\hline \multicolumn{5}{|l|}{ Parity } \\
\hline First parity & 26.4 & 10,394 & 33.6 & 61,807 \\
\hline Second parity & 28.7 & 10,934 & 34.5 & 62,484 \\
\hline Third parity & 17.2 & 6,297 & 16.6 & 33,064 \\
\hline Four or more parity & 27.8 & 9,225 & 15.3 & 33,543 \\
\hline \multicolumn{5}{|l|}{ Ante-natal care } \\
\hline No & 21.0 & 7,191 & 9.6 & 21,879 \\
\hline
\end{tabular}




\begin{tabular}{|c|c|c|c|c|}
\hline Partial & 67.8 & 24,632 & 70.9 & $1,36,617$ \\
\hline Full & 11.2 & 5,027 & 19.5 & 32,402 \\
\hline \multicolumn{5}{|l|}{ Skilled birth attendant } \\
\hline No & 50.2 & 16,182 & 16.6 & 37,685 \\
\hline Yes & 49.8 & 20,668 & 83.4 & $1,53,112$ \\
\hline \multicolumn{5}{|l|}{ Mass media exposure } \\
\hline No Exposure & 30.9 & 8,486 & 24.6 & 49,374 \\
\hline Exposure & 69.1 & 28,364 & 75.4 & $1,41,524$ \\
\hline \multicolumn{5}{|l|}{ Educational status } \\
\hline No Education & 47.4 & 14,095 & 27.6 & 55,165 \\
\hline Primary & 14.0 & 5,251 & 13.5 & 26,712 \\
\hline Secondary & 32.7 & 14,215 & 46.9 & 88,871 \\
\hline Higher & 6.0 & 3,289 & 12.0 & 20,150 \\
\hline \multicolumn{5}{|l|}{ Caste } \\
\hline Scheduled Caste & 20.0 & 6,331 & 21.2 & 35,170 \\
\hline Scheduled Tribe & 9.4 & 5,733 & 10.3 & 37,889 \\
\hline Other Backward Class & 40.0 & 11,858 & 43.6 & 74,060 \\
\hline Others & 30.5 & 12,928 & 25.0 & 43,779 \\
\hline \multicolumn{5}{|l|}{ Religion } \\
\hline Hindu & 78.9 & 25,806 & 78.9 & $1,38,343$ \\
\hline Muslim & 16.4 & 5,851 & 16.1 & 29,309 \\
\hline Others & 4.8 & 5,193 & 5.0 & 23,246 \\
\hline \multicolumn{5}{|l|}{ Wealth index } \\
\hline Poor & 45.8 & 12,622 & 44.5 & 90,521 \\
\hline Middle & 19.6 & 7,418 & 19.9 & 38,393 \\
\hline Rich & 34.6 & 16,810 & 35.6 & 61,984 \\
\hline \multicolumn{5}{|l|}{ Place of residence } \\
\hline Urban & 26.8 & 14,527 & 29.7 & 47,833 \\
\hline Rural & 73.2 & 22,323 & 70.3 & $1,43,065$ \\
\hline \multicolumn{5}{|l|}{ Region } \\
\hline North & 12.8 & 6,557 & 13.2 & 36,079 \\
\hline Central & 28.0 & 7,875 & 25.7 & 52,952 \\
\hline East & 25.3 & 5,847 & 25.4 & 39,243 \\
\hline Northeast & 4.1 & 6,965 & 3.9 & 28,825 \\
\hline West & 12.9 & 4,178 & 13.1 & 13,892 \\
\hline South & 16.9 & 5,428 & 18.7 & 19,907 \\
\hline Total & 100.0 & 36,850 & 100.0 & $1,90,898$ \\
\hline
\end{tabular}

206 Table-2 represents bivariate and logistic regression analysis estimates for women delivering

207 babies at home by their background characteristics in India. Women with age at first birth 25

208 years or more had lower likelihood to deliver babies at home in comparison to women whose

209 age at first birth was less than 18 years ( 2005-06 [OR: 0.57; CI: 0.49-0.68] and 2015-16 [OR:

210 0.76; CI: 0.76-0.82]). Women with four or more parity had higher odds to deliver babies at 
home in comparison to women with parity one (2005-06 [OR: 1.70; CI: 1.49-1.92] and 201516 [OR: 2.16; CI: 2.03-2.30]. women with full ANC had lower likelihood to deliver babies at home in comparison to women with no ANC (2005-06 [OR: 0.34; CI: 0.28-0.41] and 2015-16 [OR: 0.41; CI: 0.38-0.45]). Women who delivered babies using SBA had lower likelihood to deliver babies at home (2005-06 [OR: 0.002; CI: 0.002-0.003] and 2015-16 [OR: 0.01; CI: 0.01-0.01]) in reference to women who do no deliver using SBA. In 2015-16 women with media exposure had lower likelihood to deliver babies at home in comparison to women who had no media exposure [OR: 0.89; CI: 0.84-0.93]. Women from higher educational status had lower odds to deliver babies at home in comparison to women who had no education (2005-06 [OR: 0.33; CI: 0.26-0.42] and 2015-16 [OR: 44; CI: 0.39-0.49]). Women from rich wealth index had lower likelihood to deliver babies at home in comparison to women from poor wealth quintile (2005-06 [OR: 0.51; CI: 0.45-0.58] and 2015-16 [OR: 0.65; CI: 0.61-071]). Women from rural areas had higher likelihood to deliver babies at home in comparison to women from urban areas (2005-06 [OR: 1.94; CI: 1.76-2.14] and 2015-16 [OR: 1.12; CI: 1.06-1.18]). The regional differences in case of women delivering babies at home is quite diverse and significant change was visible in last one decade. In central India the odds of delivering babies was high in 2005-06 [OR: 1.15; CI: 1.01-1.32] whereas in 2015-16 the situation was opposite [OR: 0.92;

CI: $0.87-0.98$ ] in reference to women from north India. In case of Eastern and North-Eastern India the overall women delivering babies at home got lowered. The odds however were lower in 2005-06 (East [OR: 0.73; CI: 0.63-0.84] and North-East [OR: 0.88; CI: 0.76-1.01]) and higher in 2015-16 (East [OR: 1.37; CI: 1.29-1.47] and North-East [OR: 1.45; CI: 1.35-1.57]) in comparison to women from North India. The odds for women delivering babies at home was low in Western and Southern India in comparison to North India in 2005-06 and 2015-16.

\begin{tabular}{|c|c|c|c|c|}
\hline \multirow{2}{*}{$\begin{array}{l}\text { Background } \\
\text { characteristics }\end{array}$} & \multicolumn{2}{|c|}{$2005-06$} & \multicolumn{2}{|c|}{ 2015-16 } \\
\hline & $\%$ & $\operatorname{AOR}(95 \% \mathrm{CI})$ & $\%$ & $\operatorname{AOR}(95 \% \mathrm{CI})$ \\
\hline
\end{tabular}




\begin{tabular}{|c|c|c|c|c|}
\hline & & & & \\
\hline Age at first birth & $*$ & & $*$ & \\
\hline$<18$ years & 74.9 & Ref. & 28.9 & Ref. \\
\hline $18-24$ years & 54.8 & $0.86 * * *(0.78-0.96)$ & 18.7 & $0.95 *(0.9-1.01)$ \\
\hline 25 or more years & 25.5 & $0.57 * * *(0.49-0.68)$ & 11.4 & $0.76 * * *(0.70-0.82)$ \\
\hline Parity & $*$ & & $*$ & \\
\hline First parity & 38.9 & Ref. & 9.0 & Ref. \\
\hline Second parity & 49.1 & $1.49 * * *(1.34-1.66)$ & 15.4 & $\begin{array}{c}1.63 * * *(1.54- \\
1.72)\end{array}$ \\
\hline Third parity & 67.1 & $1.95 * * *(1.72-2.21)$ & 26.1 & $2.02 * * *(1.9-2.15)$ \\
\hline Four or more parity & 81.6 & $1.70 * * *(1.49-1.92)$ & 40.5 & $\begin{array}{c}2.16^{* * * *(2.03-} \\
2.30)\end{array}$ \\
\hline Ante-natal care & $*$ & & $*$ & \\
\hline No & 87.7 & Ref. & 43.2 & Ref. \\
\hline Partial & 56.5 & $0.70 * * *(0.62-0.8)$ & 19.2 & $\begin{array}{c}0.59 * * *(0.55- \\
0.62)\end{array}$ \\
\hline Full & 16.1 & $0.34 * * *(0.28-0.41)$ & 5.6 & $\begin{array}{c}0.41 * * *(0.38- \\
0.45)\end{array}$ \\
\hline Skilled birth attendant & $*$ & & $*$ & \\
\hline No & 99.5 & Ref. & 88.3 & Ref. \\
\hline Yes & 17.2 & $\begin{array}{c}0.002 * * *(0.002- \\
0.003)\end{array}$ & 5.0 & $\begin{array}{c}0.01 * * *(0.01- \\
0.01)\end{array}$ \\
\hline Mass media exposure & $*$ & & $*$ & \\
\hline No Exposure & 81.9 & Ref. & 37.5 & Ref. \\
\hline Exposure & 48.1 & $1.03(0.92-1.17)$ & 12.8 & $\begin{array}{c}0.89 * * *(0.84- \\
0.93)\end{array}$ \\
\hline Educational status & $*$ & & $*$ & \\
\hline No Education & 80.5 & Ref. & 36.6 & \\
\hline Primary & 61.0 & $0.83 * * *(0.73-0.94)$ & 24.7 & $\begin{array}{c}0.89 * * *(0.84- \\
0.94)\end{array}$ \\
\hline Secondary & 35.1 & $0.70 * * *(0.63-0.79)$ & 10.8 & $\begin{array}{c}0.68 * * *(0.65- \\
0.72)\end{array}$ \\
\hline Higher & 7.0 & $0.33 * * *(0.26-0.42)$ & 3.1 & $\begin{array}{c}0.44 * * *(0.39- \\
0.49)\end{array}$ \\
\hline Caste & $*$ & & $*$ & \\
\hline Scheduled Caste & 65.2 & Ref. & 19.7 & Ref. \\
\hline Scheduled Tribe & 80.7 & $1.34 * * *(1.18-1.52)$ & 30.0 & $1.08 * *(1.01-1.16)$ \\
\hline Other Backward Class & 59.7 & $1.71 * * *(1.47-2.00)$ & 17.8 & $1.40 * * *(1.31-1.5)$ \\
\hline Others & 45.8 & $1.48 * * *(1.33-1.65)$ & 15.4 & 1.02(0.97 -1.09) \\
\hline Religion & $*$ & & $*$ & \\
\hline Hindu & 58.0 & Ref. & 17.1 & Ref. \\
\hline Muslim & 64.7 & $0.84 * * *(0.73-0.96)$ & 28.1 & $\begin{array}{c}1.52 * * *(1.43- \\
1.61)\end{array}$ \\
\hline Others & 45.5 & $1.03(0.89-1.19)$ & 17.0 & $1.57 * * *(1.46-1.7)$ \\
\hline Wealth index & $*$ & & $*$ & \\
\hline Poor & 81.5 & Ref. & 31.4 & Ref. \\
\hline Middle & 58.9 & $0.75 * * *(0.66-0.85)$ & 13.4 & $\begin{array}{c}0.82 * * *(0.77- \\
0.86)\end{array}$ \\
\hline Rich & 27.8 & $0.51 * * *(0.45-0.58)$ & 6.2 & $\begin{array}{c}0.65 * * *(0.61- \\
0.70)\end{array}$ \\
\hline Place of residence & $*$ & & $*$ & \\
\hline Urban & 29.5 & Ref. & 9.7 & Ref. \\
\hline Rural & 69.1 & $1.94 * * *(1.76-2.14)$ & 22.8 & $\begin{array}{c}1.12 * * *(1.06- \\
1.18)\end{array}$ \\
\hline
\end{tabular}




\begin{tabular}{|c|c|c|c|c|}
\hline Region & $*$ & & $*$ & \\
\hline North & 59.3 & Ref. & 14.6 & Ref. \\
\hline Central & 77.1 & $1.15^{* *}(1.01-1.32)$ & 26.6 & $0.92 * *(0.87-0.98)$ \\
\hline East & 69.6 & $0.73 * * *(0.63-0.84)$ & 27.8 & $\begin{array}{c}1.37 * * *(1.29- \\
1.47)\end{array}$ \\
\hline Northeast & 70.2 & $0.88 *(0.76-1.01)$ & 28.8 & $\begin{array}{c}1.45 * * *(1.35- \\
1.57)\end{array}$ \\
\hline West & 36.2 & $0.36 * * *(0.3-0.42)$ & 9.0 & $\begin{array}{c}0.50 * * *(0.45- \\
0.55)\end{array}$ \\
\hline South & 24.7 & $0.21 * * *(0.17-0.24)$ & 4.1 & $\begin{array}{c}0.35 * * *(0.31- \\
0.39) \\
\end{array}$ \\
\hline $\begin{array}{l}\text { Total } \\
{ }^{*} p<0.001 \\
\text { ratio; } C I \text { : }\end{array}$ & \multicolumn{4}{|c|}{$\begin{array}{l}58.5 \\
\text { test of significance; } * * * p<0.001, * * p<0.05, * p<0.10 ; \text {; AOR: Adjusted odds }\end{array}$} \\
\hline
\end{tabular}

235 Figure-1 provide concentration curve for women delivering babies at home in India. It was 236 found that the value of CI increased from -0.25 to -0.39 from 2005-06 to 2015-16; this depicts 237 that the outcome variable (herein women delivering babies at home) got more concentrated 238 among women from lower socio-economic status. This is a cause of concern as poorer women are at higher risk for delivering babies at home.

Table-3 provides decomposition analysis estimates for women delivering babies at home by their background characteristics in India. The first column is for coefficients from logistic regression analysis; second and third column are for elasticity and concentration index (CI) whereas the fourth column (absolute contribution) is the product of elasticity and CI. Fifth column (\% contribution) is the proportion of absolute contribution multiplied by 100 . The main aim of the decomposition analysis is to provide explain \% contribution for socio-economic status (SES) related inequality for women delivering babies at home. Skilled birth attendant explained $70.3 \%$ and $68.6 \%$ of SES related inequality for women delivering babies at home in 2005-06 and 2015-16 respectively. Moreover, wealth index explained 8.0\% and 7.2\% of SES related inequality followed by educational status (6.1\% and 6.0\%) and region (3.8\% and 6.9\%) for women delivering babies at home in 2005-06 and 2015-16 respectively. It was interesting 
251 to observe that place of residence contributed less to explain SES related inequality for women 252 delivering babies at home in 2015-16 (0.7\%) than in 2005-06 (5.2\%).

253

254

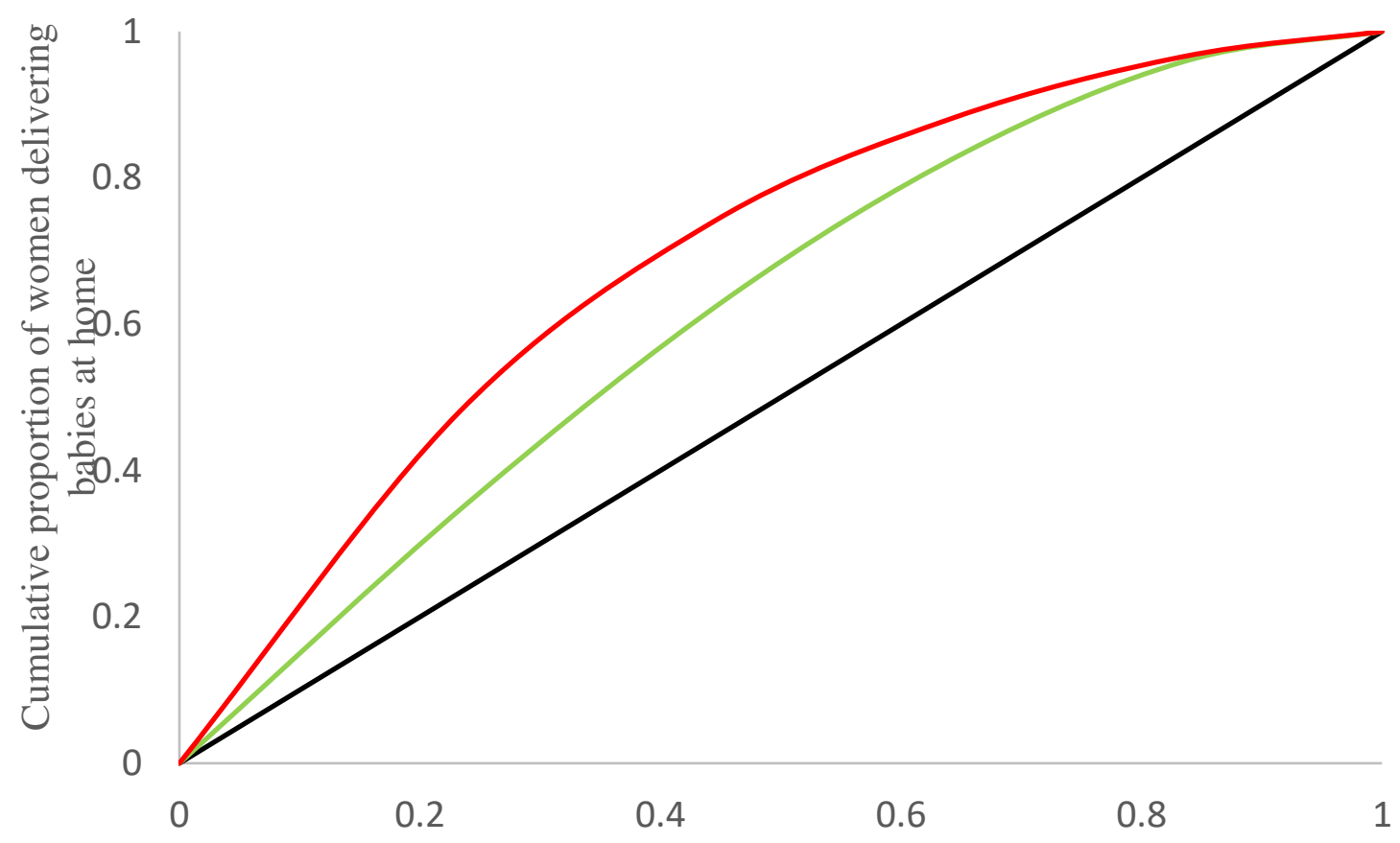

Cumulative proportion of wealth

256 Figure-1. Concentration curve for women delivering babies at home in India. 
Table 3: Decomposition analysis estimates for women delivering babies at home by their background characteristics in India.

\begin{tabular}{|c|c|c|c|c|c|c|c|c|c|c|}
\hline \multirow{2}{*}{$\begin{array}{l}\text { Background } \\
\text { characteristics }\end{array}$} & \multicolumn{5}{|c|}{ 2005-06 } & \multicolumn{5}{|c|}{$2015-16$} \\
\hline & Coefficient & Elasticity & CI & $\begin{array}{c}\text { Absolute } \\
\text { contribution }\end{array}$ & $\begin{array}{c}\% \\
\text { contribution } \\
\end{array}$ & Coefficient & Elasticity & CI & $\begin{array}{c}\text { Absolute } \\
\text { contribution }\end{array}$ & $\begin{array}{c}\% \\
\text { contribution }\end{array}$ \\
\hline \multicolumn{11}{|l|}{ Age at first birth } \\
\hline \multicolumn{11}{|l|}{$<18$ years } \\
\hline $18-24$ years & -0.148 & -0.008 & 0.065 & -0.001 & 0.4 & -0.049 & -0.008 & -0.013 & 0.000 & -0.1 \\
\hline 25 or more years & -0.555 & -0.004 & 0.408 & -0.002 & 1.1 & -0.273 & -0.003 & 0.256 & -0.001 & 1.0 \\
\hline \multicolumn{11}{|l|}{ Parity } \\
\hline \multicolumn{11}{|l|}{ First parity } \\
\hline Second parity & 0.398 & 0.008 & 0.139 & 0.001 & -0.8 & 0.489 & 0.007 & 0.090 & 0.001 & -0.9 \\
\hline Third parity & 0.669 & 0.008 & -0.040 & 0.000 & 0.2 & 0.704 & 0.006 & -0.126 & -0.001 & 1.1 \\
\hline Four or more parity & 0.528 & 0.009 & -0.280 & -0.003 & 1.8 & 0.770 & 0.008 & -0.378 & -0.003 & 4.0 \\
\hline \multicolumn{11}{|l|}{ Ante-natal care } \\
\hline \multicolumn{11}{|l|}{ No } \\
\hline Partial & -0.352 & -0.004 & 0.033 & 0.000 & 0.1 & -0.535 & -0.030 & -0.042 & 0.001 & -1.7 \\
\hline Full & -1.082 & -0.006 & 0.478 & -0.003 & 2.1 & -0.892 & -0.009 & 0.306 & -0.003 & 3.8 \\
\hline \multicolumn{11}{|c|}{ Skilled birth attendant } \\
\hline \multicolumn{11}{|c|}{ No } \\
\hline Yes & -6.182 & -0.351 & 0.287 & -0.101 & 70.3 & -4.916 & -0.647 & 0.077 & -0.050 & 68.6 \\
\hline \multicolumn{11}{|l|}{ Mass media exposure } \\
\hline \multicolumn{11}{|l|}{ No Exposure } \\
\hline Exposure & 0.033 & -0.002 & 0.185 & 0.000 & 0.3 & -0.120 & -0.013 & 0.180 & -0.002 & 3.3 \\
\hline \multicolumn{11}{|l|}{ Educational status } \\
\hline \multicolumn{11}{|l|}{ No Education } \\
\hline Primary & -0.185 & -0.002 & -0.046 & 0.000 & 0.0 & -0.116 & -0.002 & -0.203 & 0.000 & -0.4 \\
\hline Secondary & -0.356 & -0.013 & 0.350 & -0.005 & 3.2 & -0.385 & -0.014 & 0.159 & -0.002 & 3.1 \\
\hline Higher & -1.105 & -0.005 & 0.797 & -0.004 & 2.9 & -0.826 & -0.004 & 0.622 & -0.002 & 3.3 \\
\hline
\end{tabular}

14 | P a g e 


\section{Caste}

Scheduled Caste

Scheduled Tribe

0.291

Other Backward Class

0.537

0.395

\section{Religion}

Hindu

Muslim

Others

$-0.176$

0.028

0.000

0.000

0.001

0.222

0.000

0.000

0.0

0.0

0.417

0.454

0.005

0.001

0.017

0.213

0.000

0.000

$-0.1$

Wealth index

Poor

Middle

Rich

$-0.289$

$-0.667$

$-0.002$

$-0.017$

0.112

0.000

$-0.011$

0.1

7.9

\section{$-0.203$}

$-0.425$

$-0.003$

$-0.008$

0.089

0.644

0.000

$-0.005$

0.4

Place of residence

Urban

Rural

0.663

0.041

$-0.179$

$-0.007$

5.2

0.113

0.003

$-0.191$

0.000

0.7

North

Central

0.143

$-0.003$

$-0.152$

0.000

$-0.3$

$-0.007$

$-0.214$

Northeast

West

$-0.130$

$-1.030$

$-1.583$

0.001

0.000

$-0.003$

$$
-1.0
$$

0.318

0.000

0.008

0.001

$-0.127$

$-0.331$

0.000

$-0.003$

$\begin{array}{ll}-0.181 & 0.000\end{array}$

0.000

$-0.001$

$-0.021 \quad 0.207$

$-0.004$

$\begin{array}{ll}2.0 & -0.695 \\ & -1.044\end{array}$

$-0.005$

0.291

$-0.073$

$-0.391$

$-0.247$

100.0

$-0.318$

Residual

CI: Concentration Index 


\section{Discussion:}

This article attempted to examine the risk factors associated with women delivering babies at home. Also, we tried to decompose the estimates for women delivering babies at home to examine the contribution of various factors contributing to baby deliveries at home. The results found improvements, over the decade, in the prevalence of women delivering baby at home, it declined from $58.5 \%$ in 2005-06 to $18.9 \%$ in 2015-16. Despite decline in prevalence of women delivering babies at home over the decade, the result noticed increase in concentration of women delivering babies at home towards poor, it rises from -0.25 in 2005-06 to -0.39 in 201516. It means more of poor women were delivering babies at home in 2015-16 than in 205-06. Furthermore, this study noticed certain factors that were contributing to the risk of women delivering babies at home. Women with low age at first birth, with higher parity, without antenatal care, without skilled attendant at birth were more likely to delivering babies at home than their counterparts. Moreover, women who had mass media exposure, educated women, Scheduled Tribes women, women from richest wealth quintile household, and urban women were less likely to deliver babies at home than their counterparts. Skilled attendants at birth was the biggest contributory factor, during both the time-periods, which explained socioeconomic inequality in the prevalence of baby deliveries at home.

The results expectedly found huge decline in the prevalence of women delivering babies at home, a decline of around 40 percent point from $58.5 \%$ in $2005-06$ to $18.9 \%$ in $2015-16$. This decline can be attributed to the improvements in maternal and child health care services that took place in the country after 2005-06 [25], [26]. Age of the mother at their first born child is an important predictor of baby delivery at home. Results evidently concluded that as age of the mother at first birth increases, the odds of delivering baby at home declines. In other words, as age of a mother increases, there is a higher probability that she might choose institutional 
delivery over delivering her baby at home. Increasing maternal age may increase the perception of risk, thus reducing the chances of home delivery [27].

The results noticed that higher the parity, the more likely the mothers were to give birth at home. Previous studies also suggest that birth order or parity is important driver of institutional delivery and with higher parity or birth order chances of institutional delivery decreases among women, rising the odds of home delivery among them [28], [29]. The likely reason to choose home delivery by mothers with higher parity is that they perceive delivery as a normal process and develop confidence to give birth at home [30].It is plausible that after delivering the birth previously, subsequent deliveries are perceived to be of low risk, thus increasing the likelihood of delivering subsequent babies at home [27]. Women prefer to use skilled delivery care for their first delivery but then withdraw from utilizing skilled delivery services for subsequent births. This finding is interesting, however raises certain speculation for why women with higher parity do not prefer to use such services? It is because of previous unpleasant experience with institutional delivery or due to factors related to high cost associated with skilled care services or as a part of social practice [31]. Further explorations required to examine the reason for this finding.

Ante-natal care and skilled attendant at birth are another significant variables that affected the maternal choice of planning their delivery accordingly. Results from both the time-periods evidently noted that mothers who opted for ante-natal care and SBA were less likely to go for home delivery. Previous studies in various Indian settings are in line with this finding [27]. Studies conducted in other developing countries also in concordance with the finding of this study [32], [33]. Women who opt ANC and SBA are more likely to receive guidance from health professionals that may prompt them to go for institutional delivery [33]. Furthermore, those who receive ANC from the beginning of their delivery care receive motivation to opt for SBA in an institutional care during their delivery [34], [35]. 
The study noticed education status of the mother as an important predictor of mothers delivering babies at home, mothers without any education were more likely to deliver their babies at home than educated mothers. This finding is consistent with studies from other developing countries [28], [29], [36], [37]. This finding is also concordant with studies from different settings in India [38]. Educated mothers are more likely to be aware of hazards of home deliveries and therefore prefer institutional deliveries over home deliveries [38]. Furthermore, education promotes better understanding of health messages and also empowers women, thus enabling them to make their choice of opting institutional delivery [28].

During both the time-periods, wealth index was noticed as an important factor that affected the home delivery among mother. Results concluded that richer women were less likely to deliver at home than their poor counterparts. Previous studies from India also revealed similar results for association between household wealth and place of delivery [24], [39]. Women from poor households find it difficult to utilize SBA due to high out of pocket expenditures associated with institutional delivery and ended up delivering at home [40], [41]. The poor utilization of SBA among poor in India is a severe cause of concern as these services are supposed to be available to all free of cost at all government facilities. The inequitable use of SBA between rich-poor raises questions regarding the availability, accessibility, quality, and cost incurred on utilizing SBA [31]. This study further noted that women from rural areas were more likely to deliver baby at home than their urban counterparts. Previous studies in various Indian settings also agree with this finding [31]. The plausible factors can include lack of availability of skilled personnel, women's reluctance or ignorance regarding using the services, or problems related to the poor quality of care in the rural area [42].

Apparently, socio-demographic factors such as age of the mother, household wealth, parity, caste, mass-media exposure, and educational status of the mother does not contribute heavily in explaining the inequality to the prevalence of delivering babies at home in the decomposition 
analysis, even though these factors appeared to be plausible predictors of home delivery in the logistic regression model. Skilled birth attendant comes out as the single largest factor contributing to the inequality in the prevalence of deliveries at home. Furthermore, results from concentration curve revealed that most of the deliveries at home are concentrated among women in poor households and the rich-poor gap has widened in a decade. Despite introduction of National Rural Health Mission (NRHM) and other incentive scheme such as provision of free delivery care implemented in various states of India, a large chunk of poor women are still delivering their babies at home. This may be the plausible reason why skilled attendant at birth (SBA) is contributing heavily in explaining the inequality in the decomposition analysis result. Since poor women cannot afford care provided by SBA, they prefer to deliver at home, thereby raising the rich-poor inequality as explained by SBA in the decomposition model. Previous studies also noted rich-poor inequalities in the utilization of SBA in India [25], [26].

The current study is sensitive to few limitations. First, cross-sectional nature of the survey does not allow us to infer causality. Despite above limitation, this study made a reasonable attempt to examine the factors associated with home delivery among women in India.

\section{Conclusion:}

Given the encouraging evidence on the back of reduced prevalence of home delivery over the two survey period, sustained policy efforts are need of the hour to achieve further reductions in the prevalence of home-based delivery. Based on our findings, we can conclude that there is a need to promote institutional deliveries, special focus to be given to poor women, women with higher parity, uneducated women, and rural women. Furthermore, it is proposed to improve mass media exposure among women as it may indirect promote institutional delivery. Despite various efforts promoted by NRHM, much work needs to be done in the rural parts of the country as rural women were more likely to opt for home delivery than their counterparts. 
Given the preponderance of home deliveries among the poorer section of the society, every effort should be made to ensure that poor women are attended by a trained SBA. Efforts should headway to ensure that every pregnant women receive required antenatal visits, specifically in rural areas. While the thrust for minimum four ante-natal care and skilled attendant at birth should continue, it is suggested to bring more and more women under the purview of government run health schemes. Mobilizing self-help groups and strengthening women's association with community health workers might bring a change at a community level by providing requisite information related to deliveries.

\section{Abbreviations:}

ANC: Antenatal care

CC: Concentration Curve

CEBs: Census Enumeration Blocks

CI: Confidence Interval

JSY: Janani Suraksha Yojana

MoHFW: Ministry of Health and Family Welfare

NFHS: National Family Health Survey

NRHM: National Rural Health Mission

OBC: Other Backward Class

OR: Odds Ration

PPS: Probability Proportional to Size

PSUs: Primary Sampling Units

SBA: Skilled Attendant at Birth

SC: Scheduled Caste

ST: Scheduled Tribe 


\section{Declarations:}

Ethics approval and consent to participate: The data is freely available in public domain and survey agencies that conducted the field survey for the data collection have collected a prior consent from the respondent.

Consent for publication: Not applicable

Competing Interest: The authors declare that they have no competing interests.

Funding: Authors did not received any funding to carry out this research.

Author's Contribution: The concept was drafted by PK, SS, RP, and SC. PK and SS contributed to the analysis design. RP advised on the paper and assisted in paper conceptualization. SC and SPM contributed in the comprehensive writing of the article. All authors read and approved the final manuscript.

Acknowledgements: Not applicable

Availability of data and materials: The data is publically available to everyone upon request. The data can be accessed from https://dhsprogram.com/methodology/survey/survey-display$\underline{355 . \mathrm{cfm}}$ 


\section{References}

[1] World Health Organization, “Trends in maternal mortality 2000 to 2017: estimates by WHO, UNICEF, UNFPA, World Bank Group and the United Nations Population Division: executive summary," World Health Organization, 2019. [Online]. Available: https://apps.who.int/iris/handle/10665/327596.

[2] L. Hug, M. Alexander, D. You, and L. Alkema, "National, regional, and global levels and trends in neonatal mortality between 1990 and 2017, with scenario-based projections to 2030: a systematic analysis," Lancet Glob. Heal., vol. 7, no. 6, pp. e710e720, Jun. 2019, doi: 10.1016/S2214-109X(19)30163-9.

[3] Z. Lazić and I. Takač, "Outcomes and risk factors for unplanned delivery at home and before arrival to the hospital," Wien. Klin. Wochenschr., vol. 123, no. 1-2, pp. 11-14, Jan. 2011, doi: 10.1007/s00508-010-1505-z.

[4] M. F. de Almeida et al., "Accidental home deliveries in southern São Paulo, Brazil," Rev. Saude Publica, vol. 39, no. 3, pp. 366-375, Jun. 2005, doi: 10.1590/S003489102005000300006.

[5] L. Say et al., "Global causes of maternal death: a WHO systematic analysis," Lancet Glob. Heal., vol. 2, no. 6, pp. e323-e333, Jun. 2014, doi: 10.1016/S2214109X(14)70227-X.

[6] M. M. Kifle, H. F. Kesete, H. T. Gaim, G. S. Angosom, and M. B. Araya, "Health facility or home delivery? Factors influencing the choice of delivery place among mothers living in rural communities of Eritrea," J. Heal. Popul. Nutr., vol. 37, no. 1, p. 22, Dec. 2018, doi: 10.1186/s41043-018-0153-1.

[7] R. O. Moindi, M. M. Ngari, V. C. S. Nyambati, and C. Mbakaya, "Why mothers still deliver at home: understanding factors associated with home deliveries and cultural practices in rural coastal Kenya, a cross-section study," BMC Public Health, vol. 16, no. 
1, p. 114, Dec. 2015, doi: 10.1186/s12889-016-2780-z.

[8] A. Biswas et al., "Timely referral saves the lives of mothers and newborns: Midwifery led continuum of care in marginalized teagarden communities - A qualitative case study in Bangladesh," Flo00Research, vol. 7, no. 0, p. 365, Mar. 2018, doi: 10.12688/f1000research.13605.1.

[9] M. G. Mekonnen, K. N. Yalew, J. Y. Umer, and M. Melese, "Determinants of delivery practices among Afar pastoralists of Ethiopia.," Pan Afr. Med. J., vol. 13 Suppl 1, no. Supp 1, p. 17, 2012, doi: 10.11604/pamj.supp.2012.13.1.2066.

[10] F. Abebe, Y. Berhane, and B. Girma, "Factors associated with home delivery in Bahirdar, Ethiopia: A case control study," BMC Res. Notes, vol. 5, no. 1, p. 653, 2012, doi: 10.1186/1756-0500-5-653.

[11] National Health Mission (NHM), “Janani Suraksha Yojana," 2005. https://nhm.gov.in/index1.php?lang=1\&level=3\&sublinkid=841\&lid=309 (accessed Dec. 15, 2020).

[12] S. S. Lim, L. Dandona, J. A. Hoisington, S. L. James, M. C. Hogan, and E. Gakidou, “India's Janani Suraksha Yojana, a conditional cash transfer programme to increase births in health facilities: an impact evaluation," Lancet, vol. 375, no. 9730, pp. 20092023, Jun. 2010, doi: 10.1016/S0140-6736(10)60744-1.

[13] P. Sarkar and N. S. Tigga, "Social Inequality and Institutional Deliveries," Soc. Change, vol. 48, no. 1, pp. 85-103, Mar. 2018, doi: 10.1177/0049085717743840.

[14] J. P. Tripathy and S. Mishra, "Causes and Predictors of Neonatal, Post-neonatal and Maternal Deaths in India: Analysis of a Nationwide District-Level Household Survey-4 (DLHS-4), 2012-13,” J. Trop. Pediatr., vol. 63, no. 6, pp. 431-439, Dec. 2017, doi: 10.1093/tropej/fmx009.

[15] W. N. Nunu, V. Ndlovu, A. Maviza, M. Moyo, and O. Dube, "Factors associated with 
home births in a selected ward in Mberengwa District, Zimbabwe," Midwifery, vol. 68, pp. 15-22, Jan. 2019, doi: 10.1016/j.midw.2018.09.013.

[16] N. Devasenapathy et al., "Why women choose to give birth at home: a situational analysis from urban slums of Delhi,” BMJ Open, vol. 4, no. 5, p. e004401, May 2014, doi: 10.1136/bmjopen-2013-004401.

[17] B. K. Sarker, M. Rahman, T. Rahman, J. Hossain, L. Reichenbach, and D. K. Mitra, "Reasons for Preference of Home Delivery with Traditional Birth Attendants (TBAs) in Rural Bangladesh: A Qualitative Exploration,” PLoS One, vol. 11, no. 1, p. e0146161, Jan. 2016, doi: 10.1371/journal.pone.0146161.

[18] L. Muchabaiwa, D. Mazambani, L. Chigusiwa, S. Bindu, and V. Mudavanhu, "Determinants of Maternal Healthcare Utilization in Zimbabwe," Int. J. Econ. Sci. Appl. Res., vol. 5, no. 2, pp. 145-162, 2012, [Online]. Available: https://ssrn.com/abstract=2155627.

[19] J. O. Ogolla, "Factors Associated with Home Delivery in West Pokot County of Kenya," Adv. Public Heal., vol. 2015, pp. 1-6, 2015, doi: 10.1155/2015/493184.

[20] C. Wanjira, M. Mwangi, E. Mathenge, G. Mbugua, and Z. Ng'ang'a, "Delivery Practices and Associated Factors among Mothers Seeking Child Welfare Services in Selected Health Facilities in Nyandarua South District, Kenya," BMC Public Health, vol. 11, no. 1, p. 360, Dec. 2011, doi: 10.1186/1471-2458-11-360.

[21] H. K. Kasaye, Z. M. Endale, T. W. Gudayu, and M. S. Desta, "Home delivery among antenatal care booked women in their last pregnancy and associated factors: communitybased cross sectional study in Debremarkos town, North West Ethiopia, January 2016," BMC Pregnancy Childbirth, vol. 17, no. 1, p. 225, Dec. 2017, doi: 10.1186/s12884-017$1409-2$.

[22] J. Das and J. Hammer, "Are Institutional Births Institutionalizing Deaths?,” World Bank, 
2014.

https://www.worldbank.org/en/webarchives/archive?url=https\%3A\%2F\%2Fweb.world bank.org\%2Farchive\%2Fwebsite01605\%2FWEB\%2FARE_INST.HTM\&mdk=38427 3014 (accessed Dec. 16, 2020).

[23] N. Agrawal and A. Tiwari, "Determinants of home delivery among mothers in urban and rural Vadodara district, Gujarat, India," Indian J. Community Med., vol. 45, no. 2, p. 159, 2020, doi: 10.4103/ijcm.IJCM_289_19.

[24] J. Sahoo, S. V. Singh, V. K. Gupta, S. Garg, and J. Kishore, "Do socio-demographic factors still predict the choice of place of delivery: A cross-sectional study in rural North India," J. Epidemiol. Glob. Health, vol. 5, no. S1, p. S27, 2015, doi: 10.1016/j.jegh.2015.05.002.

[25] B. Ali, P. Dhillon, and S. K. Mohanty, "Inequalities in the utilization of maternal health care in the pre- and post-National Health Mission periods in India," J. Biosoc. Sci., vol. 52, no. 2, pp. 198-212, 2019, doi: 10.1017/S0021932019000385.

[26] B. Ali and S. Chauhan, "Inequalities in the utilisation of maternal health Care in Rural India: Evidences from National Family Health Survey III \& IV," BMC Public Health, vol. 20, no. 1, p. 369, Mar. 2020, doi: 10.1186/s12889-020-08480-4.

[27] A. Thind, A. Mohani, K. Banerjee, and F. Hagigi, "Where to deliver? Analysis of choice of delivery location from a national survey in India," BMC Public Health, vol. 8, no. 1, p. 29, Dec. 2008, doi: 10.1186/1471-2458-8-29.

[28] J. K. Kabakyenga, O. “ Stergren, E. Turyakira, and K. O. Pettersson, "Influence of Birth Preparedness, Decision-Making on Location of Birth and Assistance by Skilled Birth Attendants among Women in South-Western Uganda," PLoS One, vol. 7, no. 4, pp. 18, 2012, doi: 10.1371/journal.pone.0035747.

[29] A. Shimazaki, S. Honda, M. M. Dulnuan, J. B. Chunanon, and A. Matsuyama, "Factors 
associated with facility-based delivery in Mayoyao, Ifugao Province, Philippines," Asia Pac. Fam. Med., vol. 12, no. 1, pp. 1-5, Oct. 2013, doi: 10.1186/1447-056X-12-5.

[30] T. R. Feyissa and G. A. Genemo, "Determinants of institutional delivery among childbearing age women in Western Ethiopia, 2013: Unmatched case control study,” PLoS One, vol. 9, no. 5, May 2014, doi: 10.1371/journal.pone.0097194.

[31] I. Hazarika, "Factors that Determine the Use of Skilled Care During Delivery in India: Implications for Achievement of MDG-5 Targets," Matern. Child Health J., vol. 5, no. 8, pp. 1381-1388, 2011, doi: 10.1007/s10995-010-0687-3.

[32] S. Agha and T. W. Carton, "Determinants of institutional delivery in rural Jhang, Pakistan," Int. J. Equity Health, vol. 10, no. 1, p. 31, Jul. 2011, doi: 10.1186/1475-9276$10-31$.

[33] S. Dhakal, E. van Teijlingen, E. A. Raja, and K. B. Dhakal, "Skilled care at birth among rural women in Nepal: Practice and challenges," J. Heal. Popul. Nutr., vol. 29, no. 4, pp. 371-378, 2011, doi: 10.3329/jhpn.v29i4.8453.

[34] M. Carlough and M. McCall, "Skilled birth attendance: What does it mean and how can it be measured? A clinical skills assessment of maternal and child health workers in Nepal," Int. J. Gynecol. Obstet., vol. 89, no. 2, pp. 200-208, May 2005, doi: 10.1016/j.ijgo.2004.12.044.

[35] Pradhan A, "Situation of antenatal care and delivery practices," Kathmandu Univ. Med. J., vol. 3, no. 3, pp. 266-270, 2005.

[36] R. Karkee, C. W. Binns, and A. H. Lee, "Determinants of facility delivery after implementation of safer mother programme in Nepal: A prospective cohort study," $B M C$ Pregnancy Childbirth, vol. 13, no. 1, pp. 1-7, Oct. 2013, doi: 10.1186/1471-2393-13193.

[37] Z. B. Mengesha, G. A. Biks, T. A. Ayele, G. A. Tessema, and D. N. Koye, 
"Determinants of skilled attendance for delivery in Northwest Ethiopia: A community based nested case control study," BMC Public Health, vol. 13, no. 1, p. 130, Dec. 2013, doi: 10.1186/1471-2458-13-130.

[38] P. Swain, P. Singh, and S. Priyadarshini, "Determinants of home deliveries - Findings from India DLHS 4 analysis," J. Fam. Med. Prim. Care, vol. 9, no. 9, p. 4723, 2020, doi: 10.4103/jfmpc.jfmpc_751_20.

[39] A. J. Kesterton, J. Cleland, A. Sloggett, and C. Ronsmans, "Institutional delivery in rural India: the relative importance of accessibility and economic status," 2010. Accessed: Dec. 24, 2020. [Online]. Available: http://www.biomedcentral.com/1471-2393/10/30.

[40] S. K. Mohanty and A. Srivastava, "Out-of-pocket expenditure on institutional delivery in India," Health Policy Plan., vol. 28, no. 3, pp. 247-262, May 2013, doi: 10.1093/heapol/czs057.

[41] M. Perkins et al., "Out-of-pocket costs for facility-based maternity care in three African countries," Health Policy Plan., vol. 24, no. 4, pp. 289-300, Jul. 2009, doi: 10.1093/heapol/czp013.

[42] M. Koblinsky et al., "Going to scale with professional skilled care," Lancet, vol. 368, no. 9544. Elsevier, pp. 1377-1386, Oct. 14, 2006, doi: 10.1016/S0140-6736(06)693823.

\section{Figure Title and Legend:}

\section{Figure 1:}

Title: Concentration curve for women delivering babies at home in India.

Legend: Cumulative proportion of wealth 
Figures

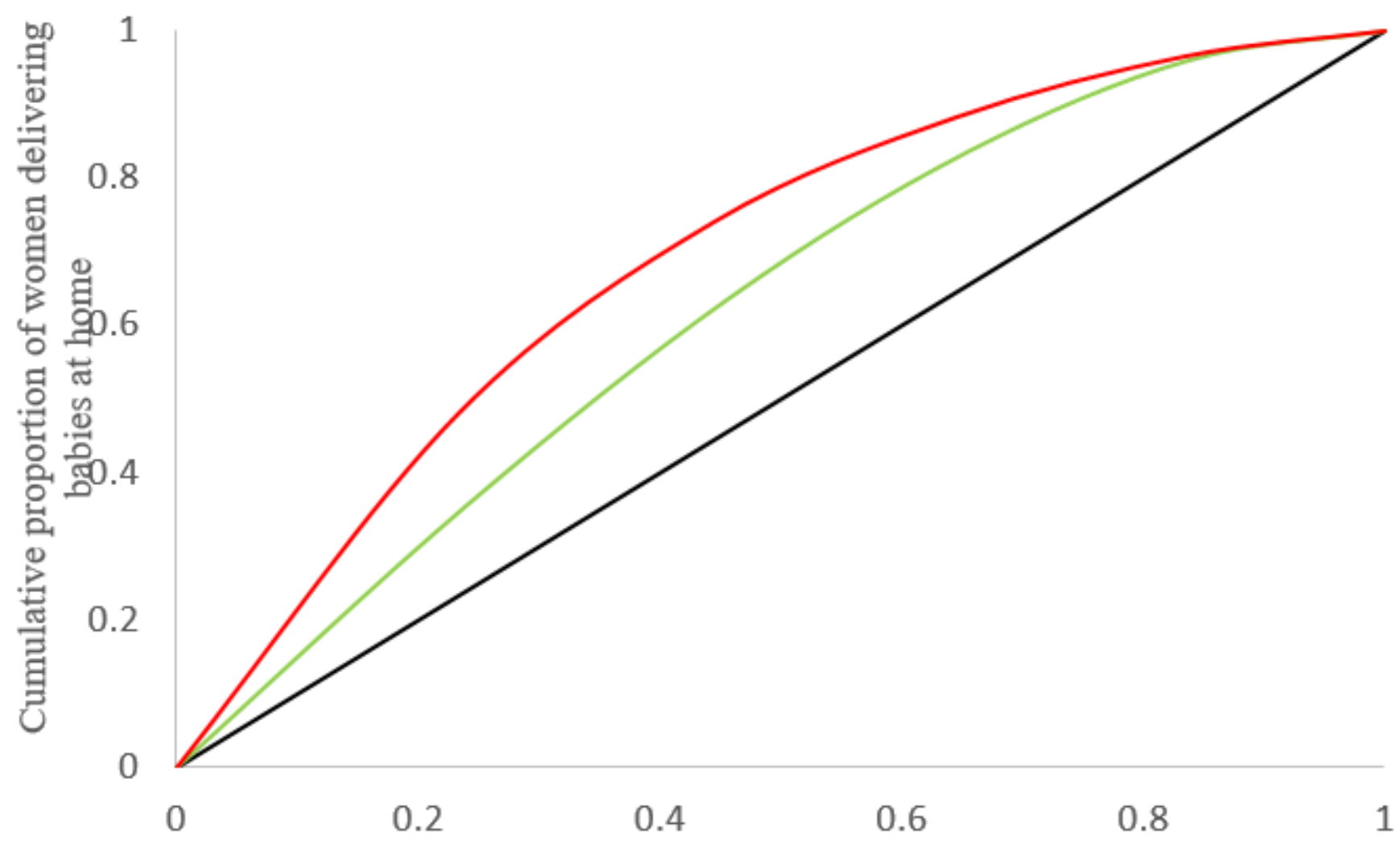

Cumulative proportion of wealth

- Line of equality $\quad-2005-06(-0.25)$

\section{Figure 1}

Concentration curve for women delivering babies at home in India. Legend: Cumulative proportion of wealth 